\title{
Vascular Endothelial Growth Factor Antisense Oligonucleotide
}

National Cancer Institute

\section{Source}

National Cancer Institute. Vascular Endothelial Growth Factor Antisense Oligonucleotide. NCI Thesaurus. Code C53435.

An antisense oligonucleotide with potential antiangiogenesis activity. Vascular endothelial growth factor (VEGF) antisense oligonucleotide binds directly to binds VEGF A/C/D mRNA, leading to mRNA degradation and the inhibition of VEGF A-mediated ang iogenesis and VEGF C/D-mediated lymphangiogenesis. 